\title{
LAS CLASES MEDIAS COMO TERRITORIO EN DISPUTA: LA UNIDAD POPULAR Y LOS FUTUROS POSIBLES
}

Azun Candina Polomer 


\section{AZUN CANDINA POLOMER}

Doctora en Historia, profesora asociada de la Facultad de Filosofía y Humanidades e investigadora del Archivo Central Andrés Bello de la Universidad de Chile. Sus áreas de docencia e investigación son la historia reciente de Chile y el Cono Sur, memoria e identidades sociales. 


\section{LAS CLASES MEDIAS COMO TERRITORIO EN DISPUTA: LA UNIDAD POPULAR Y LOS FUTUROS POSIBLES}

En su último discurso como presidente de la república, Salvador Allende tuvo palabras de agradecimiento y aliento para los obreros, campesinos, mujeres y jóvenes de su país, y llamó al pueblo a defenderse, pero no a sacrificarse. Sus términos más duros fueron contra los generales golpistas, el gran capital financiero y los colegios profesionales:

"Me dirijo a los profesionales de la patria, a los profesionales patriotas, a los que hace días estuvieron trabajando contra la sedición auspiciada por los Colegios profesionales, colegios de clase para defender también las ventajas que una sociedad capitalista da a unos pocos" (Allende, 1973).

Es significativo que, en sus últimas palabras al país y considerando el amplio abanico de opositores al gobierno, el presidente haya elegido mencionar la querella entre los profesionales que apoyaron al gobierno socialista y esos colegios profesionales, calificándolos de sediciosos y de "colegios de clase". Tal vez, desde una perspectiva de historia y memoria, no haya mejor cita que esta para iniciar una reflexión sobre las clases medias y su tensa relación con la Unidad Popular.

\section{EL MIEDO A LOS ROJOS}

Para la década de 1960, los grupos, clases, capas o sectores medios (cada cual parecía elegir la denominación que más le acomodara) eran un grupo relativamente nuevo y heterogéneo en la estructura de clases de las sociedades latinoamericanas, pero ya claramente identificable. Una de las preguntas pendientes sobre ellos era cómo reaccionarían, en términos colectivos, ante el talante revolucionario la época. ¿Cómo actuaría ese variopinto grupo de profesionales, administrativos y pequeños y medianos propietarios que había crecido notoriamente desde comienzos del siglo XX? ¿Defenderían el reformismo moderado y conciliador del así llamado "Estado de compromiso"? ¿Darían un paso más allá, sumándose a los proyectos de cambios estructurales y revolucionarios de la sociedad? ¿Girarían a la derecha? ¿Qué pasaría con sus supuestas virtudes cívicas y su espiritu republicano cuando, por ejemplo, la disyuntiva fuera entre reacción y revolución, sin mayores maquillajes? 
La clase media, por lo tanto, fue uno de los territorios de tensión política durante la Unidad Popular. No era una disputa irrelevante: para el periodo, Chile era un país con una mayoría de la población en la pobreza, contaba con un poderoso movimiento sindical obrero, una creciente sindicalización campesina y partidos y movimientos de izquierda capaces de ganar elecciones (como lo hicieron, de hecho, en 1970). Pero también era un país con una creciente clase media que se identificaba como tal, con partidos - como el Partido Radical y la Democracia Cristiana- que se publicitaban como sus representantes. Identificados con el centro, sin embargo, dichos partidos se encontraron en la más incómoda de las situaciones ante la elección de Salvador Allende: una coalición de izquierda había llegado al poder sin necesidad de incluirlos, y la derecha los acusaba de debilidad y complicidad con los marxistas. Nada aseguraba que conservarían el apoyo de las educadas, moderadas y republicanas clases medias, si es que alguna vez habían sido tan importantes para ellas. En otras palabras, en el imaginario político de la época, las clases medias se transformaron, quizás más que cualquier otro grupo social, en un territorio a conquistar, pues podrían inclinar la balanza hacia la construcción del socialismo o hacia la reacción antimarxista y restauradora del "Estado en forma" de raíz portaliana.

En esa disputa, la derecha chilena entró con velas desplegadas. A fines de los años sesenta y en la contienda electoral de 1970, organizó una agresiva campaña económica y comunicacional sobre los peligros de la revolución y la sovietización de Chile, y uno de sus objetivos principales fueron los grupos medios. Contaba, además, con medios de prensa de circulación masiva y con el apoyo irrestricto de la administración Nixon (una de sus pesadillas era la creación, en América Latina, de un "sándwich rojo", es decir, Cuba al norte y Chile al sur (Winn, 2013)) y, por lo tanto, hubo una amplia cobertura que advertía sobre la amenaza revolucionaria contra la propiedad privada, la libertad y la democracia.

En ese discurso, apelaron a valores atribuidos a las clases medias desde comienzos del siglo XX, como la moderación, la racionalidad, el esfuerzo y el orgullo por sus logros, particularmente a nivel individual y familiar. Como muestra de ello, citamos aquí las palabras de tres artículos editoriales del periódico El Mercurio, de 1972, que resumen bien esos llamados de alarma. Se definió allí a la clase media como los

"intelectuales y artistas, los que trabajan y los que piensan, los empresarios, los que organizan la industria, los que disponen el comercio, equidistantes de una minoría gastada y de mayorías incapaces, llamados a defender al individuo creador que defiende su independencia" (No dan cabida a la clase media, 1972).

Frente a los excesos y absurdos de los extremos, los llamó a ser la voz de la racionalidad: "contra sus vociferantes amenazas, la clase media sólo opone la 
realidad y el sentido común, sin dictadura, sin golpes, por voluntad de la mayoría democrática” (H. D., 1972).

En una pedagógica editorial, el periodista Mario Urzúa Aracena ilustró a los lectores de El Mercurio acerca de quiénes componían la clase media chilena; estaba la "vieja clase media", representada por pequeños agricultores, empresarios y comerciantes, y la "nueva clase media", personificada por el ejecutivo, el técnico y el burócrata. Los ejecutivos y profesionales, asociados al Estado, eran los más activos, creativos y preparados para enfrentar los cambios laborales y los desafíos del país (Urzúa, 1972). El juicio de Urzúa Aracena es que esta clase media sería la dueña del futuro, que en gran medida le sería propio en la medida que se derrotara al marxismo:

"La clase media es un producto de nuestro siglo. Por ello, tanto Marx como los liberales del siglo XIX se equivocaron rotundamente con la clase media. Marx, despectivamente, creyó en su desaparecimiento. Los liberales creyeron que la burguesía iba a triunfar definitivamente. Sin embargo, las viejas clases medias tuvieron su decadencia, como lo dijo Marx, pero nació la clase media que hoy es la más fuerte, decisiva y pujante, adversa al marxismo" (íbid.).

¿Y por qué esta clase media, creativa y esforzada, debía oponerse al marxismo? El argumento central fue que el gobierno de la Unidad Popular primero atacaría a los grandes empresarios y propietarios nacionales e internacionales, pero ya cumplido ese objetivo, les tocaría el turno de ser colectivizados, expropiados y estatizados a los medianos y pequeños propietarios y a los profesionales. Ello se convertiría en el fin de la libertad y, por lo tanto, de los derechos básicos de los individuos:

"Siguiendo impertérritos en la implantación de su utopía, los comunistas quieren hacer una propiedad social, un trabajo social y un hombre social, es decir, colectivizar al individuo, reemplazando a la persona por la sociedad [...]. Las capas sociales medias reciben hoy tranquilizantes, sobre todo después del paro gremial, pero es evidente que serán tachadas más tarde de 'voluntarismo' o 'economicismo' y de resistencia al humanismo del régimen" (No dan cabida a la clase media, 1972).

Citar artículos del año 1972 no es casual. Para esa fecha, la oposición contra la Unidad Popular se encontraba en su mejor momento desde la elección de 1970, y sus campañas estaban teniendo éxito. Era esperable que un gobierno que proponía nacionalizar riquezas básicas, estatizar la banca y oponerse al imperialismo enfrentara 
la oposición decidida de los grandes grupos económicos y empresariales, pero para 1972, habían logrado sumar también a un número significativo de asociaciones de pequeños y medianos empresarios - como los transportistas - y a agrupaciones gremiales, como el Colegio Médico y el Colegio de Abogados.

Con respecto a este último punto, el historiador Marcelo Casals ha destacado la importancia de los colegios profesionales en la política chilena del siglo XX (Casals, 2018), la que no siempre recibe el lugar que merece en los análisis políticos de nuestra historia reciente:

"Dentro de los grupos organizados de clase media, quienes mejor pudieron insertarse en el orden político y social del 'Estado de compromiso' construido a partir de los años 30s fueron los profesionales. A diferencia de otros sectores, los profesionales podían exhibir credenciales de saber especializado otorgados y reconocidos por el propio Estado y, por ende, podían reclamar un rol preponderante tanto en la estructura económica como en la administración de los asuntos públicos" (Casals, íbid.: 96).

Se trataba, por lo tanto, de agrupaciones con derechos jurídicos claros, bien conectadas y poderosas, y que habían tenido una influencia clara en la construcción del Estado y sus políticas públicas. Por lo demás, las buenas relaciones del gobierno de la Unidad Popular con los colegios profesionales fueron breves. Si bien el Colegio Médico, por ejemplo, saludó la llegada de uno de los suyos al poder y le deseó un buen gobierno (Candina, 2016), pronto las relaciones entre Allende y los colegios profesionales se agriaron y, para 1972, estaban decididamente en la oposición. Según Casals, el encono de los colegios profesionales frente al gobierno tuvo tres motivos fundamentales, particularmente para médicos, ingenieros y abogados. En primer lugar, el nombramiento de obreros en cargos directivos de las empresas socializadas, pues no los consideraban preparados y era algo que ofendía su dignidad profesional. En segundo lugar y relacionado con lo anterior, el quiebre de las jerarquías sociales, debido a los ataques a algunos profesionales a manos de campesinos y obreros organizados, frente a lo que reclamaron airadamente, $y$, en tercer lugar — particularmente desde el Colegio de Abogados-, el quiebre del imperio de la ley y el Estado de derecho, con autoridades que permitían irrupciones de obreros o manifestantes y que no mantenían el orden público (Casals, op. cit.). A ello debemos agregar también el temor a la "funcionarización", es decir, a que, en un Estado socialista, el ejercicio privado de las profesiones disminuyera hasta desaparecer, con la consecuente pérdida de ingresos; en el caso del Colegio Médico, se enorgullecían de haber sido — como gremio- los impulsores del Servicio 
Nacional de Salud, pero veían con preocupación los proyectos del gobierno sobre una estatización completa de la salud, y recibieron muy mal las críticas de Allende, que acusó al colegio de defender su privilegios y apeló a "los médicos de izquierda" para que confrontaran dicha organización (Candina, op. cit.).

Por otra parte, el llamado a defender los valores cristianos y tradicionales respecto del orden público, la familia y la pareja también fue exitoso en términos de convocatoria a las mujeres de clase alta y clase media. En su exhaustivo estudio, Margaret Power (Power, 2008) confirmó que Poder Femenino, la principal organización de mujeres opositoras a la Unidad Popular, nació como una iniciativa de mujeres de la clase alta y ligadas al Partido Nacional, pero logró superar ese origen y sumar a numerosas mujeres de los sectores medios e incluso populares y obreros, que veían con temor las políticas del gobierno de la UP hacia la planificación familiar, el aborto y el divorcio, los enfrentamientos callejeros violentos y la posible destrucción de la familia que vendría de una sovietización de la sociedad chilena, donde los hijos serían separados de sus madres y sometidos a una educación ideológica contraria a sus valores cristianos y católicos.

De tal manera, si miramos la disputa por las clases medias desde el punto de vista de las organizaciones empresariales y profesionales, la oposición a la Unidad Popular ganó la partida. Es importante destacar, también, que su éxito se basó más en el futuro de la Unidad Popular que en su presente. Aquello que más asustaba no era lo que estaba ocurriendo, sino lo que podía ocurrir si los rojos seguían en el poder: fin de las libertades individuales, económicas y políticas, totalitarismo, destrucción del bienestar duramente ganado y un gobierno de marxistas soberbios y autoritarios.

Sin embargo, cabe preguntarse si fue una victoria tan amplia o si es posible incluso calificarla como tal.

\section{LOS JÓVENES IDEALISTAS}

En un seminario sobre clases medias en América Latina, realizado en 2012 en el Archivo Central Andrés Bello, el historiador chileno-estadounidense Patrick BarrMelej planteó que un aspecto poco investigado de la historia política reciente de Chile es la relación entre clases medias y militancia de izquierda. Si bien es cierto que numerosas organizaciones gremiales y profesionales terminaron por alinearse en contra de la Unidad Popular y se convirtieron en la base social del golpe de Estado, la participación de individuos y grupos de los sectores medios en los partidos y organizaciones de izquierda también fue relevante a lo largo del siglo $\mathrm{XX}$ y en el gobierno socialista. Si, por ejemplo, en sus escaramuzas con el Colegio 
Médico, Salvador Allende apeló a "los médicos de izquierda", es porque el gremio se encontraba efectivamente dividido y en conflicto entre quienes apoyaban una salud socializada y quienes la rechazaban, y el mismo Salvador Allende era uno de esos "médicos de izquierda".

Algo parecido puede decirse de otros sectores de la sociedad y la economía chilena. Una organización como la Agrupación Nacional de Empleados Fiscales (ANEF), que se definió a sí misma como representante de la clase media asalariada y funcionaria, fue presidida en la época por Tucapel Jiménez, cuyas simpatías con el marxismo eran más bien nulas, pero la agrupación apoyó a la Unidad Popular, y su líder fundador, Clotario Blest Riffo, fue el sindicalista de izquierda más conocido y respetado del país (Candina, 2013). Las reformas universitarias de la década de 1960 y el activo movimiento estudiantil chileno también pueden ser vistas desde esa perspectiva: la extracción de clase (por usar un término del marxismo clásico) de la mayoría de las y los estudiantes universitarios era de clase media. Los militantes políticos y activistas de los procesos de reforma universitaria pertenecían a esas familias "de esfuerzo" y de la meritocracia: como muestran las fichas de matrícula de un espacio formativo como el Instituto Pedagógico de la Universidad de Chile ${ }^{1}$, quienes llegaron a la universidad en el siglo XX fueron los hijos e hijas de los comerciantes, profesionales, empleados públicos y agricultores chilenos. No fueron obreros ni campesinos los que lideraron el sueño de abrir las universidades al conjunto del pueblo y revitalizarlas, sino sus académicos, académicas y un grupo significativo de esos futuros profesionales.

Por último, si la oposición a la Unidad Popular fue exitosa al convocar a mujeres de las clases medias y populares en la defensa de los valores católicos y antimarxistas, hubo también una activa participación de mujeres de clase media en el cuestionamiento a una sociedad patriarcal y a los roles domésticos asignados a las mujeres. No fue una casualidad que la represión dictatorial haya sido particularmente feroz contra esas rojas en particular, es decir, niñas-de-familia a las que se debía castigar y disciplinar no solamente por su militancia de izquierda, sino por sus cuerpos, sus ropas, sus cabellos y sus actitudes insolentes; no fue una casualidad, tampoco, que la censura posterior al golpe de Estado alcanzara incluso a publicaciones femeninas como la revista Paula, dirigida principalmente a un público de mujeres de clase alta y media, que desde su fundación, en 1967, se atrevió a romper los marcos de las revistas-para-mujeres, centradas en la cocina, la moda y el maquillaje, para hablar,

1. En una revisión suspendida por las crisis recientes, la autora se encontraba analizando las fichas de matrícula de dicho instituto, que consignan el lugar de origen y la ocupación de padres y madres de los y las estudiantes. Se espera poder continuar ese trabajo. 
por ejemplo, de la infidelidad femenina y los anticonceptivos, y burlarse de los hombres (Varios autores, 2013; Memoria Chilena, S/F).

En resumidas cuentas, si una parte de las clases medias se sumó a la reacción, por miedo a una marea marxista que terminaría con el régimen democrático y también destruiría la meritocracia y la libertad de los individuos, otra parte abrazó el proyecto revolucionario porque vio en él una profundización de esos valores republicanos y meritocráticos, en la medida en que liberaría al país del imperialismo y los intereses mezquinos de las clases altas. Sin embargo, esa participación es mucho menos visible en las narrativas instaladas sobre la Unidad Popular.

Es posible que uno de los motivos de esa invisibilización haya sido la retórica y la estética obrera de la izquierda en Chile, que dominó el discurso, la iconografía y, en general, la representación de la izquierda durante el siglo XX. Los militantes y activistas de izquierda provenientes de la clase media tendieron a autodefinirse desde esa militancia — ser socialista, comunista, de la izquierda cristiana u otros- y no desde su origen de clase. Su trabajo y su defensa de la Unidad Popular fueron hechos desde ese espacio simbólico, es decir, su compromiso con una ideología y con las clases populares, obreras y campesinas, en una suerte de entrega ante una causa mayor.

¿Se trató lo anterior, entonces, de uno de los errores estratégicos de la Unidad Popular? Probablemente, y mirado en perspectiva, así fue. La Unidad Popular hizo intentos por conjurar la propaganda de derecha y el miedo a los rojos, es decir, por convencer a profesionales, dueños de almacenes o empleados bancarios de que el gobierno del pueblo los incluía y que su enemigo común eran los grandes empresarios y los intereses internacionales. Sin embargo, en un país donde el apoyo (al menos el electoral) a la derecha era alto y no solía bajar del 40 por ciento del electorado, y donde la propaganda anticomunista tenía ya una tradición y se incrementó desde la campaña electoral de 1970 en adelante, ese esfuerzo no fue suficiente. Tampoco colaboró, por cierto, lo mencionado en el párrafo anterior: contaban con numerosos militantes y activistas de izquierda que sí pertenecían a las clases medias, pero que rara vez reivindicaron públicamente su origen de clase en su activismo, e incluso, tendieron a ocultarlo.

Pero estaban allí. Según el Informe Valech de 2004, de las casi 25.000 personas que voluntariamente se presentaron y declararon haber sido víctimas de la represión dictatorial, un 30,1 por ciento declaró que al momento de ser detenidos se desempeñaban como empleados, oficinistas, comerciantes o trabajadores de servicios públicos o industrias. Los profesionales, técnicos y estudiantes fueron un 15,3 por ciento del total. Sabemos que se trata de datos parciales, dado que muchos y muchas que fueron objeto de prisión política y tortura no se presentaron a la comisión y su situación no quedó registrada, pero los datos valen, al menos, como 
una muestra de que, si la represión post golpe de Estado afectó con tanta dureza a personas que pertenecían a esos sectores medios, cabe poner en duda que esa juventud idealista de clase media haya sido una minoría.

\section{LA TRAICIÓN DICTATORIAL Y LAS LECCIONES DE UNA CRISIS}

Ironías, si se quiere, de la historia y sus zigzagueantes derroteros: muchas de las asociaciones de transportistas, comerciantes, pequeños propietarios y profesionales celebraron el golpe de Estado de 1973 como el fin de una amenaza a su forma de vida y sus expectativas de futuro, pero en los años siguientes fue la dictadura civilmilitar la que restringió su poder y sus sueños.

Para fines de la década de 1970, el gobierno terminó con la afiliación obligatoria a los colegios profesionales y les quitó importantes atribuciones en torno al resguardo de la ética profesional y el ejercicio de la profesión. La apertura de la economía chilena a los mercados y las importaciones - porque la libre competencia era, por cierto, lo mejor para el país - exterminó parte importante de la industria local, como la textil y de electrodomésticos, incapaces de competir con los bajos precios de los productos importados. La jibarización del Estado y de las empresas estatales y semiestatales hizo que uno de los principales pivotes del crecimiento y estabilidad de las clases medias chilenas, el trabajo en el Estado, fuera una oportunidad cada vez más huidiza y difícil de conseguir. La privatización de la educación superior también hizo más difícil y costoso uno de los grandes sueños de la clase media: que sus hijos e hijas llegaran a la universidad y fueran profesionales. No fue una sorpresa, entonces, que muchos de esos decepcionados activistas y grupos dejaran de apoyar "la obra" del general Augusto Pinochet y que, para la década de 1980, se sumaran a la oposición democrática.

Contradictoriamente, entonces, quienes temieron al proyecto socialista porque restringiría sus posibilidades de movilidad social, su estabilidad laboral y su bienestar, se encontraron con que la gesta liberadora de 1973 fue paulatinamente destruyendo las políticas públicas redistributivas y proteccionistas que habían hecho posible su existencia como clases medias. Solo unos pocos salieron favorecidos con el cambio: el personal de las Fuerzas Armadas y de Orden, por ejemplo, que conservó e incluso mejoró sus beneficios sociales de salud, previsión y retiro; una minoría de nuevos empresarios (los emprendedores) que tuvieron éxito en las inestables aguas del mercado; y los grandes grupos empresariales, que concentraron cada vez más la riqueza nacional.

La experiencia de la Unidad Popular, por lo tanto, debería hacernos reflexionar sobre los discursos progresistas y de cambio social, y la manera en que circulan 
públicamente. En sociedades donde grupos significativos —o la mayoría de la población- se definen como clase media, los discursos en contra del cambio estructural y su "desorden" o "caos" pueden ser muy efectivos, pues se trata de grupos particularmente sensibles a ese temor. Por otra parte, una izquierda que los olvida o los deja en segundo lugar en su retórica y su convocatoria se arriesga a que, efectivamente, ellos entiendan que tendrán que optar entre "orden" o "caos", o entre sumarse a una identidad proletaria y popular (en la que no se reconocen) o sufrir las consecuencias de su distancia. 


\section{REFERENCIAS}

Allende, S. (1973). "El último discurso de Salvador Allende", disponible en https://www.salvador-allende.cl/discursos/golpe-militar/

Candina, A. (2013). Clase media, Estado y sacrificio: la Agrupación Nacional de Empleados Fiscales (1943-1983). Santiago: LOM Ediciones.

(2016). "Studying Other Memories: The Colegio Médico de Chile under Socialism, Dictatorship, and Democracy, 1970-1990", Latin American Perspectives, 43(6), pp. 75-87.

CASAls, M. (2018). "Estado, contrarrevolución y autoritarismo en la trayectoria política de la clase media profesional chilena. De la oposición a la Unidad Popular al fin de los Colegios Profesionales" (1970-1981), Izquierdas, 44, pp. 91-113.

No dan CABida a la Clase media (20 de noviembre, 1972). Editorial, El Mercurio.

H.D. (3 de marzo, 1973). "La gran clase media”, El Mercurio, p. 3.

Memoria Chilena (S/F). "Revista Paula y feminismo, 1967-1977", disponible en http://www.memoriachilena.gob.cl/602/w3-article-100797.html

Power, M. (2008). La mujer de derecha. Elpoder femenino y la luch a contra Salvador Allende. 1964-1973. Santiago: Dibam.

UrzúA, M. (15 de febrero, 1972). "La clase media: el fiel de la balanza", El Mercurio, p. 3.

Varios autores (2013). Historias de Paula. Santiago: Ediciones UDP - Catalonia.

Winn, P. (2013). La revolución chilena. Santiago: Lom Ediciones. 